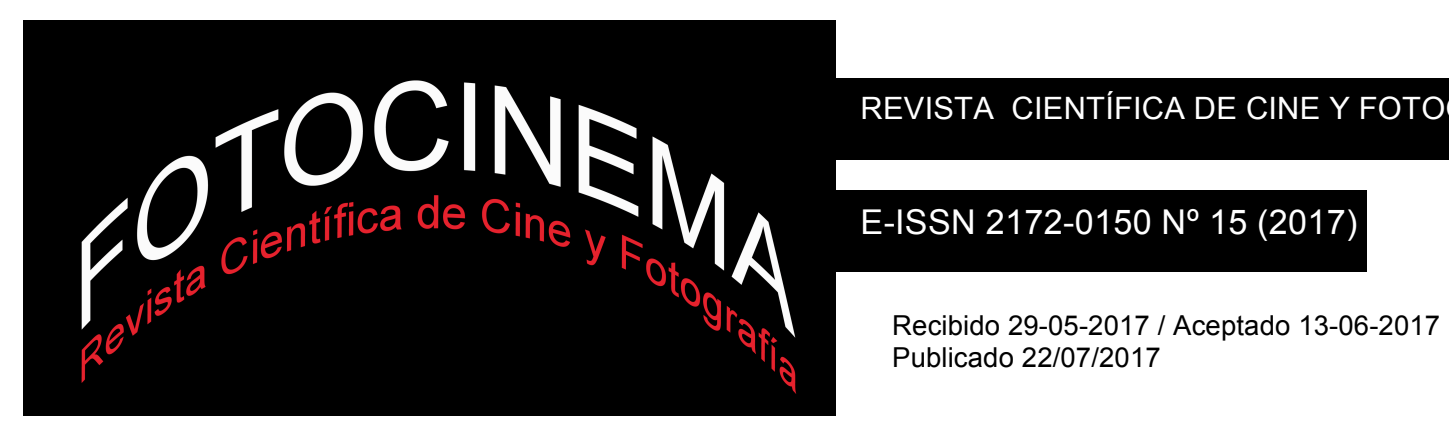

\title{
¿UN OZU PORNOGRÁFICO? HENTAI KAZOKU: EL EXPERIMENTO VENÉREO DE SUO MASAYUKI
}

\section{A PORNOGRAPHIC OZU? HENTAI KAZOKU: SUO MASAYUKI'S EXPERIMENTAL PORNO-FILM}

\author{
Antonio Santos \\ Universidad de Cantabria \\ antonio.santos@unican.es
}

\section{Resumen:}

El primer largometraje que realizara el cineasta japonés Suo Masayuki en 1983, Hentai kazoku : Aniki no o yome-san (Una familia anormal: La mujer de mi hermano mayor) plantea una combinación aparentemente imposible: se trata de una atrevida parodia de las historias familiares de Yasujiro Ozu, pero realizada bajo las convenciones del cine pornográfico. El resultado es insólito y transgresor: una evocación del cine de Ozu, rodado con su austero estilo característico, y con unos protagonistas que evocan los personajes interpretados por Setsuko Hara y Chishu Ryu, pero filmados bajo claves eróticas. Una parodia, al fin y al cabo, tan insólita como explosiva. El propósito de este experimento cinematográfico, que aúna mímesis e ironía, no se ve motivado tanto por el gesto iconoclasta, cuanto por el deseo de rendir un desenfadado homenaje al maestro por el que se siente veneración. El presente trabajo analiza los pormenores de tan singular película, reconociendo en ella las huellas del director de Cuentos de Tokio, al tiempo que se identifican en sus escenas los límites y las convenciones del roman poruno.

\begin{abstract}
:
The first feature film directed in 1983 by the Japanese Filmmaker Suo Masayuki, Hentai kazoku : Aniki no o yome-san (Abnormal family: Older Brother's Bride) departs from an apparently impossible mix: a daring parody of Yasujiro Ozu's classical family films, but shot under the conventions of the pornographic cinema. The result is unusual and shaking: an evocation of Ozu's creative world, shot with his characteristic severe style and with his recurrent characters performed by Setsuko Hara and Chishu Ryu, but translated into an erotic tale. Conceived as an explosive and irreverent parody, this experimental film links mimesis with irony. Its final target is not only the iconoclastic purpose, but the breezy homage paid to the revered master. This work analyzes such an uncommon film, trying to recognize along its images the traces of Ozu, as well as the limits and conventions of the roman poruno.
\end{abstract}

Palabras clave: erotismo; pornografía; Pinku Eiga; Roman poruno; Suo Masayuki; Yasujiro Ozu.

Keywords: Eroticism; Pornography; Pinku Eiga; Roman Poruno; Suo Masayuki; Yasujiro Ozu. 
Cómo citar: Santos, A. (2017). “¿Un Ozu pornográfico? Hentai Kazoku: el experimento venéreo de Suo Masayuki, de Michael Ninn”. Fotocinema. Revista científica de cine y fotografía, $\mathrm{n}^{\mathrm{0}}$ 15, pp. 203-228. Disponible: http://www.revistafotocinema.com/

En el desnudo, todo lo que no es bello es obsceno.

(Bresson, 1997, p. 101)

\section{Sexo, rito, pasión}

La palabra erotismo nace del dios griego Eros, el Amor. El término, del que proviene el calificativo erótico, se refiere al amor sensual: a la exaltación o descripción del amor físico en las relaciones humanas, así como en la literatura y en el arte. Es fuente de placer y de gozo porque la actividad de Eros tiene como fin último la eudaimonía: la felicidad. Y ésta se logra y se colma a través de la contemplación, la cópula y, en ocasiones, mediante la reproducción de los seres humanos. Sin embargo la órbita de Eros es transitoria, fugaz, y por tanto imperfecta e insuficiente. Por esto mismo puede ser también fuente de pesar, de frustración y desdicha. No en vano Platón subordinaba el genuino sentimiento erótico a la forma ideal que sólo se encuentra en la Belleza que trasciende el mero contacto físico (Trías, 1979, p. 35).

Pero hoy no nos corresponde tanto hablar de erotismo, cuanto de pornografía. Y conviene que comencemos por precisar los términos. Esta segunda palabra deriva etimológicamente de otros dos vocablos griegos: porné (ramera) y grafos (describir). Esto es: la pornografía, o tratado de la prostitución, se refiere al arte y prácticas de las meretrices. En los usos de nuestro lenguaje, el calificativo pornográfico se aplica a obras de marcado contenido obsceno. Lo obsceno, por su parte, se vincula con lo impúdico, lo soez, o lo ofensivo al pudor: la exaltación de la lascivia y de los impulsos más primarios. 
Erotismo y pornografía son términos próximos que, a menudo, se confunden. En cualquier caso, no es posible establecer una metodología eficaz que permita discernir un concepto de otro. Y, de existir, debería ser aplicado por la perspectiva personal de cada lector o espectador en su apreciación de una obra relacionada con el amor físico. Sea como fuere, sí que es posible establecer una sistemática conforme a la percepción individual de la representación erótica. En palabras de Gerard Lenne,

lo que se llama corrientemente erotismo y lo que llamamos pornografía, incluso si los términos están mal escogidos, incluso si su utilización es generalmente peyorativa, funcionan como dos engranajes complementarios e inseparables del mismo fenómeno. Puede percibirse incluso que el reparto de sus funciones supone que uno no podría existir sin la otra. El erotismo es lo que se desarrolla "en la cabeza", es una función cerebral. La pornografía es lo que hacen los cuerpos y el espectáculo que producen: es una función corporal. El erotismo es imaginativo, la pornografía es demostrativa. El erotismo son los fantasmas, es decir, representaciones imaginarias (Freixas \& Bassa, 2000, p. 24).

Cedamos la palabra a uno de los cineastas españoles que mejor han sabido integrar las pulsiones sexuales en sus películas, Vicente Aranda, quien se manifiesta con rotundidad: "quiero dejar constancia de que el sexo es promiscuo siempre” (Freixas \& Bassa, 2000, preliminares). Y debe quedar claro que, según nuestro Diccionario de la Lengua, lo promiscuo tiene dos acepciones: si por un lado se refiere al libertinaje sexual, por otro distingue aquello que tiene dos sentidos o se puede usar de un modo ambivalente. Y esto es así porque el juicio sobre la representación erótica ha de depender siempre de la perspectiva de su espectador. Desde este punto de vista, los condicionantes culturales, religiosos y éticos orientarán decisivamente la valoración de cada cual. Imposible resulta dogmatizar al respecto.

No cabe duda que el sexo es un estímulo muy poderoso. D.H. Lawrence moraliza al considerar que la pornografía insulta y envilece la práctica sexual, máxime en una civilización, la nuestra, que "ha confinado el sexo a los bajos fondos, y la desnudez al W.C.” Al cabo, "sin clandestinidad no habría pornografía”. Su efecto sería múltiple, 
aunque siempre pernicioso sobre su consumidor: no en vano se manipulan y pervierten, según aprecia el autor de El amante de Lady Chatterly, unos impulsos primarios, "pues cada hombre está hecho más por sus deseos inconscientes que por los conscientes. Soy lo que soy, no sólo lo que pienso que soy" (Lawrence, 1979, p. 7). Por tanto el erotismo y la pornografía -ponga cada cual el límite donde juzgue oportuno- exteriorizan deseos ocultos; sacan a la luz fantasmas soterrados en lo oscuro del inconsciente. Tienen, a menudo, una componente onírica, y se suelen relacionar con la noche, la oscuridad, el sueño: el estado de aislamiento y de inhibición absolutos. Para Susan Sontag, la pornografía tiene un único objetivo: "la animación de un conjunto de fantasmas, independientes de la forma verbal [o visual, añadiríamos], pues el lenguaje no tiene, en este sentido, más que una importancia menor, y puramente instrumental”.

Desde su perspectiva, la obra pornográfica "no representaría sino una reproducción de los fantasmas de la vida sexual". Pero al mismo tiempo es producto de una patología social, que muestra el estado malsano de una cultura. No sobra recordar cómo la literatura pornográfica se desarrolló en Europa tras la Ilustración. A partir de aquí, y de acuerdo con la escritora norteamericana,

los males provienen de falta de educación, y represión de raíces religiosas. El cada vez mayor número de publicaciones perversas estaría en relación directa con las desastrosas consecuencias de la actitud represiva de la moral cristiana en materia de sexualidad, al igual que con una ignorancia fundamental de las bases fisiológicas (Sontag, 1979, p. 24).

Cedamos la palabra, para terminar, a una de las voces más elegantes y perspicaces con que han contado las letras españolas a lo largo del siglo XX. Para Octavio Paz "erotismo es sexo y pasión, no en bruto, sino transfigurados por la imaginación: rito, teatro" (Arqués, 1979, p. 5). Desde nuestra perspectiva cabría añadir una palabra más; tal vez la definitiva: cine. 


\section{Pinku Eiga o Roman Poruno}

En Japón el sexo tuvo una representación más lúdica y festiva, una plasmación más desinhibida y cotidiana, a través de los maestros del ukiyo-e, o de la literatura licenciosa representada en autores como Saikaku Ihara, desde principios del siglo XVIII. La tradición erótica japonesa llegó al cine, pero tardíamente, y siempre atacada por la censura. Sólo a finales de los años 50 comenzaron a mostrarse abiertamente las escenas que anteriormente habían sido púdicamente veladas. El cine erótico japonés cuenta con peculiaridades: se permiten abundantes dosis de sadismo y de violencia, pero se impide mostrar explícitamente los sexos. Eufemísticamente la censura se refiere a la prohibición de mostrar vello púbico, pero el tabú no se limita a las pilosidades; tampoco se pueden mostrar explícitamente los coitos. En consecuencia, el cine erótico japonés acostumbra a derivar más hacia vertientes violentas o sadomasoquistas, de las que hallaremos una pequeña muestra en la película de Suo Masayuki a la que nos referiremos en breve.

La prohibición se ve compensada por la imaginativa forma de sugerir la actividad sexual. Es muy habitual la presencia de líquidos permisibles sobre los cuerpos de los actores: sudor, saliva, bebidas -agua y leche en particular-que sustituyen las prohibidas secreciones genitales. La mujer se muestra a menudo como esclava sexual, al servicio de todos los caprichos del varón. Al menos hasta que Nagisa Oshima alteró la norma, haciendo de Abé Sada la protagonista, dominadora y superviviente sobre su pareja en El imperio de los sentidos (Ai no korîda, 1976). Como observa Tony Rayns en un ilustrativo ensayo, "Japón es el único país cuya industria de cine erótico ha seducido tanto a los cineastas noveles como a los cineastas más radicales y transgresores. Los primeros encontraron un camino comercial en el que hacer los primeros méritos; los segundos encuentran en este género un eficaz instrumento para el discurso subversivo" (Rayns, 1995, p. 26).

Las primeras películas eróticas comenzaron a filmarse en Japón a comienzos de los años 6o, justamente en el momento en que el sistema de estudios comenzaba a resquebrajarse. La potencia industrial que alcanzará a partir de entonces el cine 
erótico llega a extremos de permitir la supervivencia a una de las grandes compañías cinematográficas japonesas, y además la más antigua de todas. En efecto: para evitar la bancarrota, la otrora hegemónica Nikkatsu hubo de especializarse en la producción de largometrajes pornográficos de bajo presupuesto. De este modo en 1972, justo el año en que se celebraban los 60 de su fundación, Nikkatsu comenzó a basar una parte significativa de su produción en las oportunamente llamadas Roman-poruno Eiga (películas romántico-pornográficas).

Se trataba de productos de serie baja, realizados con muy escaso presupuesto y de breve duración: entre 60 y 70 minutos. La mayoría de ellas se realizaban en cuatro o cinco días, y eran destinadas a sesiones dobles o triples, que eran distribuidas y exhibidas en los circuitos propios de los que disponía la compañía, o en los de otras distribuidoras subsidiarias. Son proyectadas en salas especialmente reservadas para este tipo de obras. Posteriormente, y tras su exhibición en dichas salas, aún conocerán una posterior distribución en vídeo.

Sin embargo la permisividad dista mucho de ser absoluta: las normas de autocensura establecidas por la propia industria cinematográfica son particularmente rígidas con estas producciones, hasta el punto de prohibir la exhibición de órganos genitales. Sólo recientemente algunas producciones extranjeras avaladas por su prestigio artístico, como La bella mentirosa (La belle noiseuse, Jacques Rivette, 1991), Orlando (Sally Potter, 1994), o Eyes Wide Shut (Stanley Kubrick, 1999), han relajado la norma, permitiendo la exhibición de estas partes del cuerpo siempre que no aparezcan en un contexto de actividad sexual. En realidad muchas películas occidentales de exhibición regular son mucho más explícitas, sexualmente hablando, que las comedidas eroductions niponas (Rayns, 1995, p. 28).

$\mathrm{Al}$ margen de estos condicionantes, y de la exigencia de incluir cuatro o cinco escenas de contenido erótico, se concedía una cierta libertad a los directores, que podían hacer gala de creatividad e ingenio dentro de los cauces establecidos. En 1974 el Roman-poruno didácticamente titulado Yojo-han fusuma no urabari (El mundo de las geishas), dirigido por Tatsumi Kumashiro, sorprendió a propios y a extraños al 
ser galardonado con el prestigioso Número Uno de la revista especializada Kinema Junpo. Al año siguiente, la cinta de Noboru Tanaka Jitsuroku Abe Sada (La verdadera historia de Abe Sada, 1975) figuró entre las diez mejores del año, según la citada revista. Dicha obra contaba, aunque de una forma mucho menos elaborada e intensa, los mismos acontecimientos que inspirarían, en 1976, a Nagisa Oshima su célebre Ai no korîda. Precisamente por su explicitud sexual, y por la abundante muestra de órganos genitales en plena actividad, El imperio de los sentidos sufrió las iras censoras. En julio de aquel mismo año la policía secuestró un libro en el que se reproducía el guion, acompañado de numerosas fotografías. Tanto el libro como el largometraje fueron acusados de obscenidad, y llevados a los tribunales. Sólo en 1979, tras un largo y polémico juicio, fueron ambos declarados inocentes. La película, sin embargo, sólo se exhibió en Japón en una copia que desenfocaba numerosos planos, y repartía abundantes aspas por los cuerpos desnudos de los actores. De este modo, y en palabras del propio director, El imperio de los sentidos se convirtió en la perfecta obra pornográfica japonesa, porque no puede verse en su país de origen: allí hasta su existencia misma es pornográfica (Oshima, 1992, p. 253).

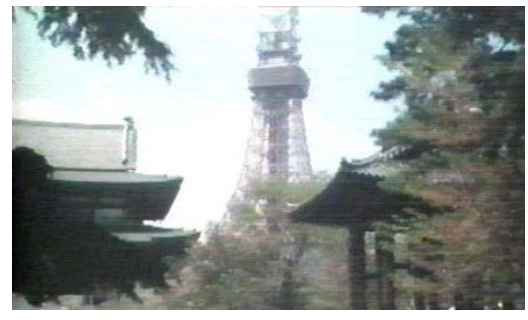

F 1

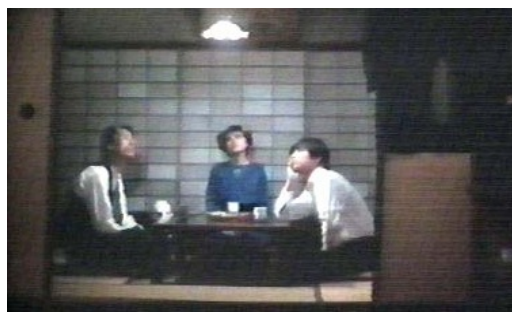

F 2

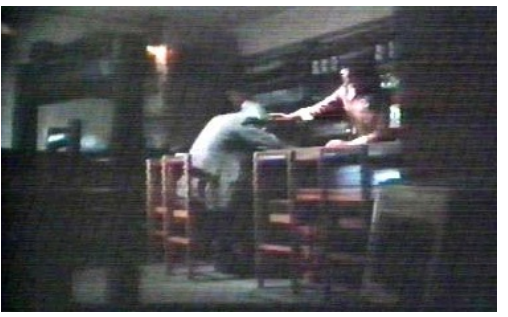

F 3

Entretanto Nagisa Oshima había ultimado su díptico en 1978 con Ai no borei ( $E l$ imperio de la pasión). Dos años atrás Noboru Tanaka aportó otro título clásico del Roman-poruno: Yaneura no Sanposha (Transeúnte en el ático, 1976). Además hay que contar multitud de producciones en vídeo realizadas por pequeñas compañías independientes. Aunque evidentemente no todas las producciones del género alcanzaban cotas de calidad equiparables a los títulos destacados, desde mediados de 
los años 70 no quedaba más remedio que examinar con seriedad la industria de películas pornográficas japonesa.

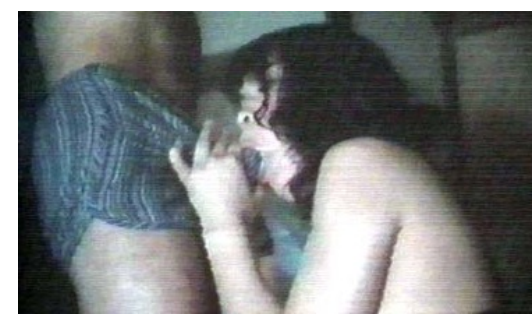

$\mathrm{F} 4$

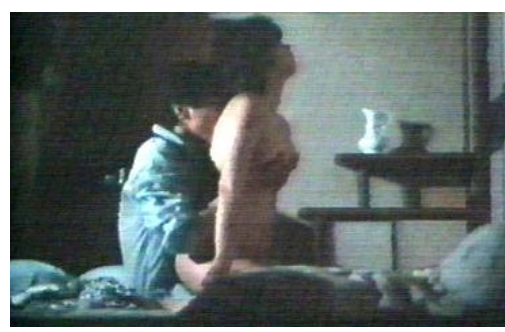

F5

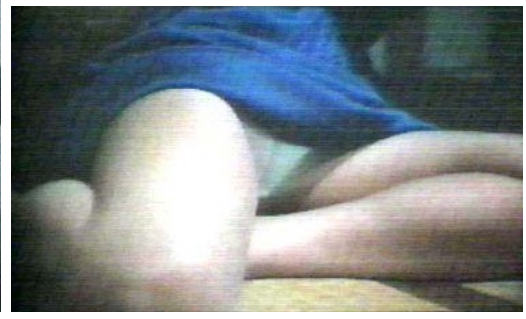

F6

Estas han recibido otros variados nombres eufemísticos: Eroductions (síncopa de Erotic Productions), Pinku Eiga (películas rosas -pink-, vinculadas con el soft core convencional), o Bara Eiga (bara es el nombre japonés que recibe la rosa del rosal), aplicadas éstas al soft-core de temática homosexual. El nombre proviene de cierta revista gay titulada Barazoku: La familia de las rosas (Rayns, 1995, p. 27).

Al igual que las Pinku Eiga convencionales, también las Bara Eiga ven restringida su libertad a la hora de filmar las escenas eróticas: no pueden mostrar genitales masculinos, ni en estado de flaccidez ni mucho menos en erección. Todo lo más, permite que se aprecie su contorno a través de unas muy ajustadas prendas interiores. Esto se comprobará en la película de Masayuki que se comenta a continuación ( $\left.\mathrm{F}_{4}\right)$.

Pese a una existencia tan accidentada, y a las numerosas restricciones, no es posible negar la evidencia: el cine erótico japonés ha legado un importante muestrario de aportaciones originales y valiosas, debido a su gran poder de seducción, a su energía visual y a la capacidad de sortear las prohibiciones, sin renunciar a su naturaleza y voluntad transgresoras. Nagisa Oshima, el más importante de los cineastas de su generación, se convirtió en un apasionado defensor del cine pornográfico, al que además ofrendó la obra maestra más relevante del género: El Imperio de los sentidos, una pieza de culto y un clásico indiscutible del cine. Otros muchos cineastas japoneses reputados dieron sus primeros pasos en el entorno del cine pornográfico. 
Algunos de ellos fueron nombres importantes en la industria del cine: Yoshimitsu Morita, Ryuichi Hiroki, Banmei Takahashi, Shusuke Kaneko o Shinji Somai. Un caso verdaderamente llamativo, por su apropiación de fuentes venerables, ha sido el de Suo Masayuki, al que hemos de prestar atención en las siguientes páginas.

\section{La anormalidad familiar según Suo Masayuki}

Shigehiko Hasumi, que llegará más adelante a ser Rector de la Universidad de Tokio, y autor de uno de los textos sobre Ozu más importantes escritos en Japón (Hasumi, 1998), instruyó a un nutrido grupo de estudiantes de cine. Entre ellos figuran algunos de los cineastas japoneses más prometedores del momento: Kiyoshi Kurosawa, Hirokazu Koreeda, Akihito Shiota, Makoto Shinozaki y Suo Masayuki entre otros; pero hoy nos interesa destacar particularmente a este último.

Masayuki se familiarizó con la historia y estética del cine cuando estudiaba en la universidad de Rikkyo. Según recuerda en una entrevista, el profesor Hasumi les enseñó por encima de todo a centrar su atención en lo que veían en la pantalla, antes que extraviarse en el contexto de producción, o en los rasgos biográficos del artista (Ehrlich, 1998b, p. 96).

Al margen de su preparación teórica, Suo Masayuki hubo de formarse como ayudante de dirección de pinku eiga: películas eróticas de bajo presupuesto. No se trata de un hecho caprichoso o coyuntural: otro tanto les sucede a otros muchos cineastas japoneses. De este modo, el primer largometraje que realizó Masayuki, reconcilia su formación en el género roman poruno, o pornográfico con la fascinación que siente por el cine de Yasujiro Ozu. He aquí una combinación aparentemente imposible: una atrevida parodia del cine de Ozu, realizada bajo las convenciones del cine pornográfico. El título completo de su opera prima es Hentai kazoku: Aniki no o yome-san (Una familia anormal: La mujer de mi hermano mayor, 1983). 
En el curso de distintas entrevistas, Masayuki reconoce el tributo de admiración que rinde al director de Cuentos de Tokio (Tokyo monogatari, Yasujiro Ozu, 1953), a quien descubrió cuando era un estudiante:

Cuando veía películas de Ozu me sentía completamente dichoso desde el principio hasta el final. Me resistía a abandonar ese mundo que Ozu había creado. Comprendía que la generación de directores más veteranos (como Masahiro Shinoda y Yoshida Yoshisige) necesitaban rechazar a Ozu con el fin de definir sus propios estilos, ya que no era "políticamente correcto" en aquellos días admirar las películas de Ozu. Pero yo no podía evitarlo: eran entonces, y lo siguen siendo ahora, mis favoritas.

Pese a todo, y a su modo de ver, el ritmo que imprimía Ozu a sus relatos no se ajusta bien con el cine de nuestros días. "Por esta razón [continúa] mi cortometraje Sararîman Kyôshitsu (Un aula para hombres de negocios, 1986), que trataba de reproducir un ritmo como el de Ozu en una producción contemporánea, resulta tan raro, tan extravagante" (Ehrlich, 1998a, p. 22). En posteriores declaraciones, Masayuki reconoce sentirse cautivado por el sentido del humor de Ozu, que aflora incluso en momentos dramáticos:

En la tumba de Ozu sólo aparece grabada una palabra: Mu, la Nada. La gente nace sola, y sola muere. Es la inevitable aceptación de nuestra absoluta soledad lo que hace tan profundo el sentido del humor en las películas de Ozu. Y es esta singularidad de su obra la que me ha cautivado tanto. (Cita Ehrlich, 1998b, p. 96).

Otro de los cineastas con los que aprendió, y compañero de formación en la comedia, fue el malogrado Juzo Itami (Tampopo, Marusa no onna), a quien dedicó dos documentales en vídeo. Y de los cineastas occidentales admira al director de La regla del juego (La règle du jeu, Jean Renoir, 1939), un clásico que considera muy divertido. A su modo de ver "al igual que Ozu, Renoir permite a todos sus personajes que se comporten como son. Sabemos que todo el mundo se encuentra esencialmente solo. Lo más importante mientras permanezcamos con vida es tratar de comprender a los otros, y no recluírnos en ese aislamiento" (Ehrlich, 1998b, p. 96). 
Tony Rayns se refiere al primer largometraje de Masayuki, al que a continuación nos referiremos, como "un brillante pastiche porno del cine de Ozu, rodado con el característico estilo de encuadre y montaje de Ozu, y un reparto que incluía réplicas de los personajes interpretados por Setsuko Hara y Chishu Ryu" (Rayns, 1995, p. 26). Se trata, en efecto, de una parodia, pero realizada en claves de cine pornográfico: una mezcla sin duda tan insólita como explosiva. El propósito no se impulsa tanto por el gesto iconoclasta, cuanto por el deseo de rendir un desenfadado homenaje al maestro por el que se siente veneración.

También la tercera película de Masayuki, Shiko funjatta (Sumo sí, sumo no, 1992), se encuentra en el vecindario de un género practicado por Ozu: las gakusei mono, o historias de escolares. Del mismo modo que La mujer y la barba (Shukujo to hige, Yasujiro Ozu, 1931) era una comedia sobre un estudiante que practica el kendo, esta trata de un grupo de universitarios que, como complemento de sus clases, deciden practicar el sumo. Por otra parte el trabajo de Masayuki más conocido fuera de su país, Shall we dansu? (1996) revisa el subgénero sarari mono, consagrado a los asalariados, al que tantas veces se acercó Ozu a lo largo de su carrera.

Recogemos aquí declaraciones del propio Masayuki: "Si me preguntan qué tipo de película es la que me gusta, no puedo responder. Me gustan las películas divertidas. La gente que vea mis películas pueden pensar que son comedias; pero se trata de algo diferente" (Ehrlich, 1998b, p. 94). Y, en efecto, sus obras tienen un sello de distinción. Las historias de Masayuki recuerdan aquel Japón tradicional, que sin duda a él le resulta más lejano que al director de Primavera tardía (Banshun, 1949), con una simpatía entre nostálgica y arqueológica. No hay lugar para lamentos ni para elegías, pero sí para recordar el pasado como una legítima fuente sobre la que reconocer el tiempo contemporáneo.

La filmografía realizada hasta la fecha por Suo Masayuki refleja con tono irónico las relaciones entre hombres y mujeres en el Japón de las dos últimas décadas del siglo XX, y las dos primeras del XXI. Tanto en Aniki no oyome san como en su obra más conocida, la exitosa Shall we dansu?, conviven mujeres de distintas edades que 
condicionan la actividad del hombre, quien pierde la hegemonía para situarse en una situación cuando menos de paridad con ellas. Se trata de una generación criada y educada en la democracia posbélica, que en modo alguno se resigna a someterse a los dictados del patriarca.

En Shall we dansu?, que conoció un remake norteamericano protagonizado por Richard Gere (Shall we dance? ¿Bailamos? Peter Chelsom, 2004), la práctica del baile establece una situación de igualdad entre hombres y mujeres. Pero no se debe olvidar que es la esposa quien ejerce la autoridad sobre el hogar. Hasta el punto que el hombre debe actuar a hurtadillas de aquella. La directora de la academia de baile, que fascina como si de una sirena danzarina se tratase, es una mujer. Es ella quien lleva el paso de danza, y quien alecciona a los torpes o grotescos varones. En la equiparación entre sexos, como sucede en La mujer de mi hermano, se basa la armonía social y familiar. Recogemos una vez más testimonios del cineasta: "Espero que Shall we dansu? contriburá a corregir el estereotipo del asalariado japonés, retratado como un robot carente de emociones, y que ayudará a promover la idea de que la honestidad en las relaciones humanas es importante" (Ehrlich, 1998a, p. 22). El protagonista de Shall We Dansu? responde al nombre de Sugiyama, que es como se llamaba la familia de Crepúsculo en Tokio (Tôkyô boshoku, Yasujiro Ozu, 1957). Recuérdese que los Mamiya de la anterior Hentai Kazoku asimismo coinciden onomásticamente con otras familias de Ozu. Pero además uno de los personajes que aparecen en la película se llama Aoki, que era el verdadero nombre del actor infantil de Ozu por excelencia: Tomio Aoki, alias Tokkan Kozo. El actor que interpreta a este personaje es Naoto Takenaka, a quien debemos una memorable interpretación del exuberante danzarín latino al estilo japonés.

Por su parte, la profesora se llama Mai (interpretada por la actriz y bailarina Tamiyo Kusaraki, quien se casó con el director de la película). Mai significa, literalmente, "Danza". Y el nombre es adecuado, puesto que es el baile en estado puro lo que seduce al personaje, y no la belleza de la profesora, con la que el protagonista no tiene ninguna aventura extraconyugal. 
Sugiyama es un personaje de edad madura, que se siente repentinamente hechizado por los bailes de salón: un tipo de música -vals, música latina- que es popular en Occidente, pero que resulta ajeno por completo a la cultura popular japonesa. Se debe tener en cuenta que las danzas en las que los bailarines de distintos sexos entran en contacto no estaban bien vistas en Japón. El propio título, que comparte términos en inglés con la adaptación japonesa de la palabra dance -Shall we dansu?se refiere tanto a la intrusión de usos culturales extranjeros en Japón, como a su adaptación a la propia idiosincrasia nipona. De este modo, tanto a partir del uso del lenguaje como de la propia práctica del baile, el cine de Masayuki nace fruto de una cultura híbrida.

\section{Los lúbricos Mamiya}

Prestemos ahora nuestra atención a la opera prima que dirigió Masayuki en 1983, y en la que se homenajea expresamente a Ozu: Hentai kazoku: Aniki no o yome-san, cuyo título principal se traduce literalmente como Una familia anormal, o pervertida. Cuenta con otros títulos alternativos para su distribución en vídeo: Novia de Primavera o, sencillamente, y limitando la traducción al subtítulo, La mujer de mi hermano.

Tiene su razón de ser el que una película como la presente comience con la Tokyo Tower, tal como sucedía en Otoño tardío (Akibiyori, Yasujiro Ozu, 1960) (F1). Del mismo modo que dicho monumento es imitación, casi hasta la parodia, de la Tour Eiffel parisina, Aniki no Oyome san será un ejercicio de mímesis rebajada y juguetona del admirado maestro: un cultismo cinematográfico realizado con indisimulada voluntad paródica. El propio formato establece una crucial diferencia: Suo Masayuki filma su película en pantalla apaisada, un procedimiento que nunca llegó a utilizar Ozu.

Pero al mismo tiempo las imágenes preliminares cumplen una función equiparable a las que tuvieran en los referentes que se pretende parodiar. Como sucedía en los 
precedentes canónicos de Ozu, una sucesión de planos espaciales aproximan la acción hasta el ingreso en la casa. La Torre de Tokio se alza sobre tejadillos de construcción tradicional, evidenciando una vez más la eterna pugna entre lo viejo y lo nuevo, que conviven en Japón y en la obra de Ozu, como asimismo sucede en el caso de sus epígonos.

Nos situamos a principios de los años 80, en un entorno familiar reconocible. Y como en los modelos originales, la mayoría del relato transcurre en interiores, en el reducido confín doméstico. El abrigo que pende de la pared aparece como preámbulo de entrada a la casa. Es esta una estampa hogareña que se repite más veces, equiparable a otras imágenes similares en Ozu: Primavera precoz (Sôshun, 1956), Otoño tardío (1960), Tarde de otoño (Samma no aji, 1961).

Dando por válido el título, se tendrá ocasión de comprobar que el comportamiento de los Mamiya de esta parodia licenciosa dista mucho de la normalidad. El padre es viudo y, aunque situado en las antípodas de Chishu Ryu, comparte con este su soledad y su afición desmedida al sake. Tiene una hija y dos hijos, el mayor de los cuales está casado: otro tanto sucedía con los Hirayama de Tarde de otoño, con cuyos nombres además coincide: el padre se llama Shuhei, y el hijo menor Koichi.

En el interior de la casa, la familia anormal a la que se refiere el título se congrega en torno a la mesa; sin embargo no están atentos a los manjares, o a la compañía. Muy por el contrario prestan una singular atención a lo que sucede encima de sus cabezas (F2). En el piso superior, en efecto, se encuentra una pareja haciendo el amor sin ningún recato; ella gime estruendosamente ( $\left.\mathrm{F}_{5}\right)$. Es más: se enfatizan acústicamente los jadeos de la mujer, que llaman la atención de su familia tanto como el comienzo puede sorprender al espectador desprevenido. Siguiendo el modelo visual de Ozu, la cámara se dispone en posición baja al tiempo que la planificación se resuelve mediante tomas estáticas que rodean a los personajes.

Pero al mismo tiempo se respeta la norma pornográfica japonesa. Como es ley en el roman poruno, no se muestran genitales; lo que no impide hiperbolizar el coito. Mientras la familia se ocupa en distintas actividades que sin duda les llevan varias 
horas de trabajo, la pareja no para de copular. Y es que el hermano mayor, Kazuo, se ha casado recientemente, como en tantas películas de Ozu; pero esto no supone la quiebra de la familia, sino más bien la congregación lúbrica de los Mamiya en torno a la actividad de alcoba de los recién casados. En el piso inferior el hermano pequeño, vivamente excitado por el espectáculo acústico con que les obsequia la cuñada, muestra atracción incestuosa por su hermana, en cuyas interioridades se fija concupiscente (F6). Sus miradas lascivas anticipan la consumación del acto adúltero e incestuoso que cometerá con su hermana política, la mujer de su propio hermano, en las escenas posteriores.

Tras este singular comienzo, que sin duda sorprenderá por su intrusión en el apacible orden de Ozu, recuperaremos numerosas imágenes y personajes característicos del cineasta japonés. A las ya citadas cabe añadir ahora que las escenas se puntúan mediante espacios vacíos, previamente abandonados por los personajes. En el exterior los callejones oscuros agrupan bares y restaurantes como tantos otros vistos en Ozu, en uno de los cuales halla refugio el padre (F3). A semejanza de los Somiya y Hirayama de ejemplos anteriores, el anciano Mamiya se presenta bajo la apariencia de un viudo solitario y borrachín, quien huye de la lubricidad de su familia para gozar de la compañía de una camarera que no tardará en desvelarnos sus ocultas habilidades.

De este modo, y a través de una sucesión de escenas paralelas, asistimos a las vicisitudes familiares: mientras la pareja de recién casados se entrega a la pasión, sus hermanos espían en el piso de abajo, y el padre se emborracha en el bar. Esta vez el anciano trata de seducir a una camarera, para finalmente quedarse dormido. Como sucede a menudo en las películas de Ozu, las mujeres con las que se encuentra el padre le recuerdan a su esposa fallecida. Más tarde, de regreso a casa, también el padre contempla con deseo a su nuera, sobre la que, sin embargo, no llega a poner nunca las manos encima.

Son numerosos los recursos visuales que Masayuki toma de Ozu, con inequívoca voluntad paródica: la familia anormal se llama Mamiya, como la de Principios de 
verano (Bakushu, 1951); así se llamaba, además, uno de los conspiradores matrimoniales de Otoño tardío. A esta coincidencia onomástica hay que añadir la usurpación paródica del canon original. Los personajes son filmados de perfil; ladean sus cabezas en tres cuartos para dirigirse a sus contertulios, para finalmente recuperar la posición en perfil, mirando ensimismados hacia el horizonte, como asimismo es habitual en Ozu. De vuelta al hogar, el hijo menor reprocha a su padre sus excesos con el sake, tal como sucedía en Tarde de otoño, el referente más próximo a esta parodia. En el curso de una conversación familiar incluso en dos ocasiones se alude al manjar que intitula una película de Ozu: El sabor del té verde con arroz (Ochazuke no aji, 1952). Hasta la música de orquesta, una variante farandulera de las partituras de Kojun Saito, refuerza la intención paródica de su realizador.

A semejanza del cineasta homenajeado, se evitan los signos de puntuación convencionales; antes bien se puntúa mediante imágenes tópicas que aluden a la primavera, y que se rinden por igual a su uso irónico: el sakura, el lago, el colegio. Pero aún existe otro procedimiento de transición graduado rítmicamente, de marcada procedencia irónica: por tres veces se repite la imagen plácida de unos vecinos que pasean por una zona ajardinada y frondosa. La primera vez se recortan iluminados por una luz irreal, al tiempo que saludan al unísono al padre. El idílico matrimonio ejecuta movimientos bien sincronizados, estableciendo una composición sojikei que asimismo era habitual en Ozu. En su segunda aparición veremos que ella está embarazada, y por último les despediremos con un hijo en los brazos (F16), una dichosa fecundidad que contrasta con los otros dos matrimonios quebrados: él es viudo, y ella ha sido abandonada por el marido. Cabe añadir que, pese a su intensa actividad sexual, los voluptuosos Mamiya no han tenido descendencia.

Efectivamente, el paso de la feliz pareja no solamente alude al paso de los meses respondiendo al designio cíclico característico de Ozu. De igual manera parecen surgir como evocaciones o ensoñaciones de la vida familiar que pasó, o que anheló el 
anciano, pero que ahora, dada su viudedad y el talante vicioso de sus hijos, se ha perdido sin remedio.

Emulando los hábitos de composición característicos de Ozu, se compartimentan los espacios, merced a las peculiaridades arquitectónicas de las casas japonesas, para sobreencuadrar a sus pobladores en sucesivas franjas. El frecuente paso del tren, sea en plano general o frente a los personajes, marca y puntúa las escenas. Buen conocedor del cine de Ozu, Masayuki reutiliza el ferrocarril, vehículo de la modernidad tan habitual en su modelo, para establecer las elipsis: el tren pasa por la mañana y por la noche, estableciendo la dinámica cíclica característica del cineasta parodiado.

Cuando el marido y la mujer se reencuentran, no tardan en reanudar su infatigable actividad amatoria. Masayuki no se resiste a filmar planos-detalle del cuello semi desnudo del marido, lo que despierta el deseo de la mujer: un procedimiento convencional que no tendría cabida en el severo canon de Ozu. Pero en el entorno de Masayuki cumple otra función adicional: adentrarnos en los procelosos recovecos sádicos que asimismo esconden los anormales Mamiya.

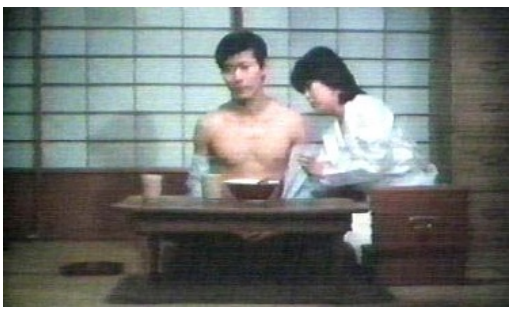

F7

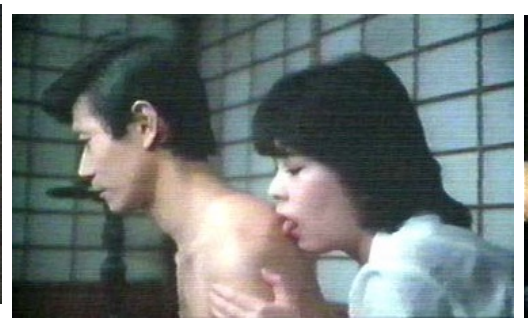

F8

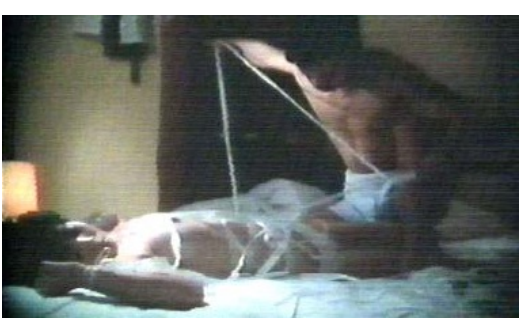

F9

En efecto, el marido se presenta con la espalda cubierta de llagas, fruto de sus aventuras sadomasoquistas. Para darle consuelo, la solícita mujer lame con fruición sus heridas (F7 y F8). Más adelante continúan con prácticas de tormento y sumisión, a las que tan aficionado es el marido: él la ata en la cama con plásticos hechos tiras, como si fuera una araña envolviendo a su presa (F9). Mientras ella aparece desnuda, el hombre suele mostrarse púdicamente cubierto con camisa. Por lo demás Yuriko, su 
mujer, se descubre como una ninfómana de rompe y rasga, circunstancia que el marido sobrelleva con razonable predisposición. En todo momento se insiste en el placer y en el deseo que embriagan a la hembra, aunque no tanto al varón. Además, y respondiendo a una norma de solidaridad institucional, sus estruendosas maniobras eróticas son espiadas por el resto de la familia con una mezcla de envidia y admiración. Los amantes carecen de intimidad, puesto que en todo momento son espiados por sus golosos parientes, y siempre por el impertinente espectador, a la sazón un intruso en medio de esta familia adicta a la práctica de la escopofilia. De hecho la posición baja de la cámara, característica de Ozu, parece ahora tomar el punto de vista de un mirón agazapado para solazarse en los momentos de intimidad ajena (F7, F8 y F9).

Siguiendo los hábitos del maestro, en estos momentos de voluptuosidad incluso se altera el raccord. Durante el coito, los dos amantes son filmados mirando indistintamente hacia la izquierda o hacia la derecha. En el contexto en que se producen estas transgresiones, habituales en Ozu, el efecto alcanza un nuevo sentido: diríase que el estado de ingravidez en que se halla la pareja hubiera afectado al propio montaje.

\section{Viva erótica}

Afortunadamente Masayuki controla su experimento paródico lo suficiente como para evitar que se le vaya en exceso de las manos. De este modo, el desenfado e impudicia a la hora de adoptar el modelo original no se aparta en exceso de la voluntad homenajeadora, que también la tiene. En la mayoría de las escenas eróticas la cámara no se recrea en el detalle, y prefiere apelar al distanciamiento y la insinuación, tal como es preceptivo en las restrictivas pinku eiga. El ejercicio sexual se traza de forma aún púdica. Los desnudos se ven tamizados por sombras, ropas o por el agua en la que se sumergen. En la mayoría de las escenas las telas cubren a discreción todas las partes pudendas. Incluso las caricias en las zonas genitales 
siempre llevan la piadosa cobertura de prendas íntimas. Matizando el aforismo bressoniano con que se encabeza el presente trabajo, cabría decir que la erótica de esta película no es bella, aunque tampoco sea específicamente obscena. Siendo justos, bastaría con calificarla de irónica o paródica.

El desnudo nunca es integral; como se dijo, en ningún momento se muestra la genitalia. Incluso en los episodios en que se practica el sexo oral, el hombre atrapa su miembro con la mano, con lo que queda oculto a la cámara, o bien es cubierto por oportunos ropajes (F4). En todo momento, por lo tanto, se evitan los planos detalle característicos del hard-core, dando como resultado un producto pornográfico que nos atreveríamos a calificar aún de tímido o de recatado. Y este recato erótico lleva a Masayuki a una solución que hubiera sido inimaginable en la obra del maestro homenajeado: el marido acaricia a la esposa, al tiempo que la mira, visiblemente excitado. La cámara adopta entonces su punto de vista. Justo entonces ella dice "no"; para a continuación taparle los ojos con la mano, que es dirigida francamente al objetivo (F10). El espectador, que actúa como fisgón, al igual que los descomedidos familiares, llega a ocupar de este modo intrusivo la posición del marido: un intrusismo que la propia mujer, ávida de alguna intimidad, se encarga de atajar. A continuación la hermana, que asimismo les espía, igualmente cierra los ojos, como asintiendo a la observación de la espiada: hay límites que la escopofilia no debe transgredir (F11). Ni siquiera por parte del espectador de una pinku eiga.

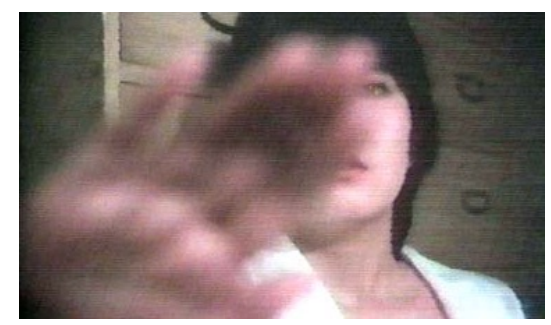

F10

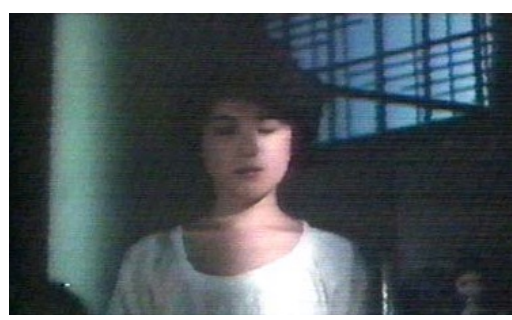

F11

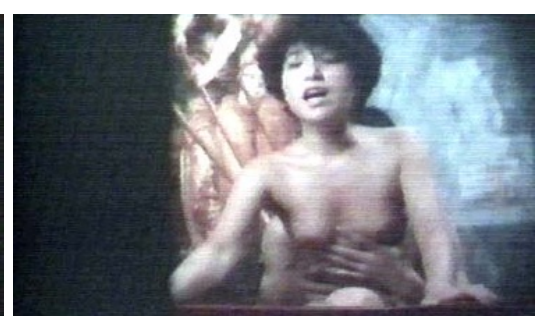

$\mathrm{F} 12$ 
Esta exigencia dará un giro radical a la película. En efecto, interrumpiremos nuestra observación de los ritos eróticos de la pareja, para centrarnos en los del resto de la familia, no menos pintorescos. A lo largo de los siguientes episodios, tendremos ocasión de reconocer distintos momentos característicos de la filmografía de Ozu, que rápidamente se verán desvirtuados por la vertiente ero-paródica. La hija se desplaza en tren al trabajo. Sin embargo, no tardaremos en recibir detalles aleccionadores sobre la forma en que la muchacha se gana la vida. Tras salir de la casa, la hermana grita orgasmáticamente, en lo alto de un puente, como liberándose de las ataduras domésticas y laborales. Lo que hace con pleno sentido, pues se dirige a desempeñar su profesión oculta, ya que ejerce como prostituta en una sauna erótica: un ninfeo lúbrico, repleto de esculturas y de pinturas licenciosas de ascendencia clásica. De este modo averiguaremos que la hermana menor, tan cándida e inocente, tiene en realidad una doble vida, como Chikako en La mujer de Tokio (Tokyo no onna, Yasujiro Ozu, 1933); o como Tokiko en Una gallina al viento (Kaze no naka no mendori, Yasujiro Ozu, 1948), películas en las que la mujer se entregaba al lenocinio para sacar a su familia a flote. Mediante un recurso de montaje sincopado se describen las distintas maniobras eróticas que la desenvuelta muchacha efectúa sobre su cliente (F12).

En otra escena, donde se alteran genéricamente las convenciones de Historia de $O$, el hombre es atado entre dos columnas, mientras la torturadora le flagela y derrama cera hirviendo sobre la piel desnuda (F13). La priapea del macho se manifiesta sin disimulo, aunque oculta por la prenda interior de la víctima (F14). Incluso a través de la misma, su dueña le practica la felación (F4). Pero merece la pena advertirse una solución invertida: es ella la torturadora, y él la víctima. Asimismo en el coito es frecuente que sea la hembra quien se sitúe encima, en posición dominante. Es ella quien goza, y quien domina a su compañero, en una situación que ya ejemplificó el cine japonés con El imperio de los sentidos. 


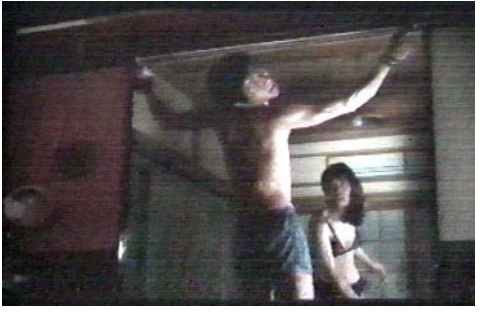

$\mathrm{F} 13$

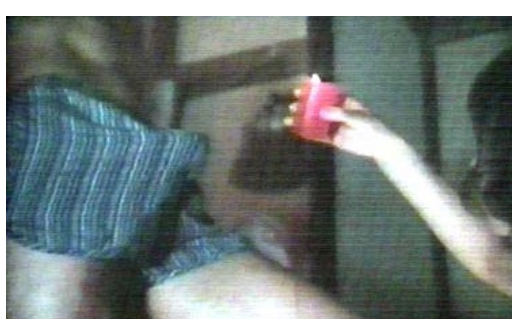

F14

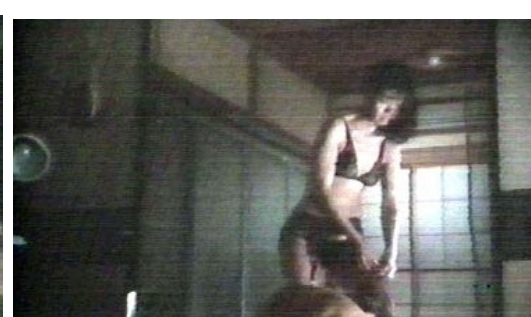

F15

Tras la placentera sesión de tortura, el hombre cae abatido a los pies de ella, sumiso aun para procurarla placer oral, al tiempo que, en un nuevo gesto humillante, ella orina sobre su cara (F15). La lluvia dorada que mana de la mujer apaga al mismo tiempo la vela con que previamente atormentara a su víctima. Diríase que con este gesto está consumiendo a la par el deseo del macho, pues es sólo ella quien goza, imponiéndose en todo momento sobre su víctima.

Respondiendo al plan paródico previamente forjado, los episodios libidinosos alternan con los homenajes explícitos a Ozu. No solamente se utilizan, a lo largo de toda la película, los recursos formales característicos del maestro -cámara baja, ausencia de movimientos, sobreencuadres de los personajes y uso de espacios intermedios para puntuar-. Asimismo se homenajean explícitamente algunos episodios bien conocidos: este sería el caso de la escena de pesca en la que el padre y el hijo mecen las cañas al unísono. La acción se sitúa junto al río, con los dos hijos de pie, y con el cesto del preceptivo color rojo (F17). Dicha escena, cabría añadir, se encuentra más cercana a la primera Historia de hierbas flotantes (Ukigusa monogatari, Yasujiro Ozu, 1934) y a Érase un padre (Chichi ariki, Yasujiro Ozu, 1942), que a la posterior Hierbas flotantes (Ukigusa, Yasujiro Ozu, 1959), en que padre e hijo pescaban frente al mar, sentados en el rompeolas, pese a que las dos guardan en común el uso del color.

Mientras el padre y el hijo pescan y se mueven al unísono, la hija, que les vigila por detrás, se dirige a ellos. Como en Cuentos de Tokio, se desdoblan los espacios de uno y otro. Detrás del hijo aparece un paisaje límpido y bucólico, presidido por el agua. 
Detrás de su padre, por el contrario, se ve la imagen de un puente colgante, emblema de tránsito, muy similar al que se vio detrás del nieto en una escena de Cuentos de Tokio, entre otras películas en las que interviene esta construcción -El sabor del arroz con té verde, Primavera tardía y Primavera precoz-, por citar los ejemplos más sobresalientes. Las soluciones de plano/contraplano respetan la continuidad de miradas; ellos miran hacia la izquierda, ella hacia la derecha. Otro tanto sucederá en una posterior escena entre el padre y la hija, en la que él mira hacia la izquierda, y ella hacia la derecha, incumpliendo con la habitual transgresión de Ozu.

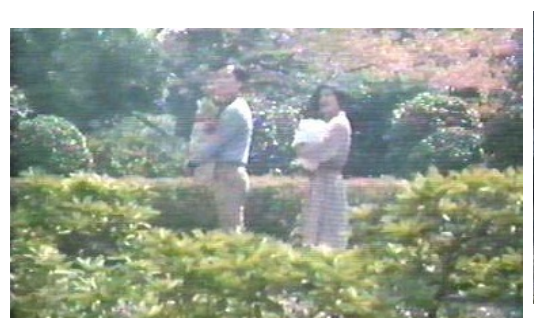

F16

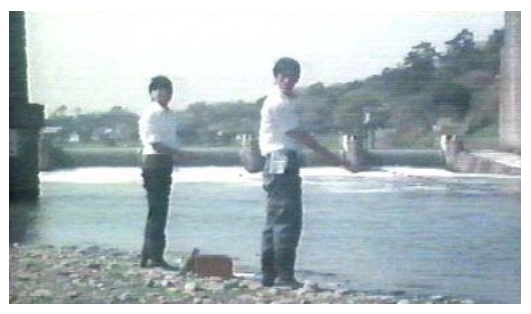

F17

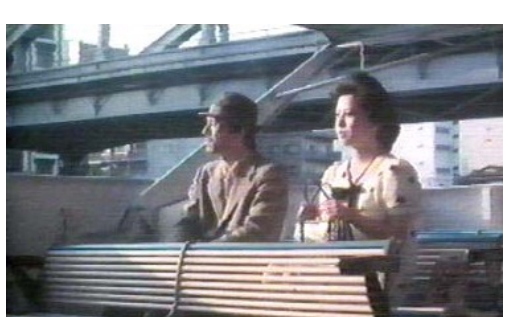

F18

En otra escena los personajes recorren el río Sumida a bordo de un barco, desde donde se trazan algunos trávelin en torno a las orillas: he aquí una variante fluvial de la excursión en autobús de Cuentos de Tokio (F18). Se repite asimismo la famosa escena del albergue de Primavera tardía. Esta vez se trata del matrimonio Mamiya quien está durmiendo. Se ven los juncos a través del shoji (F19, F20 y F21).

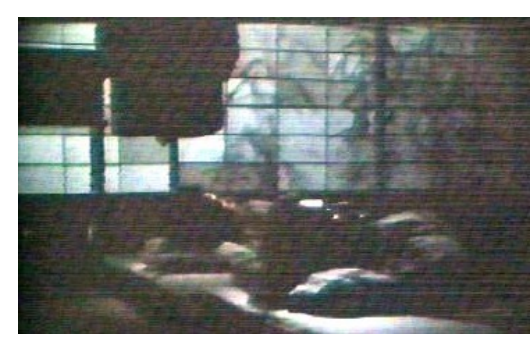

F19

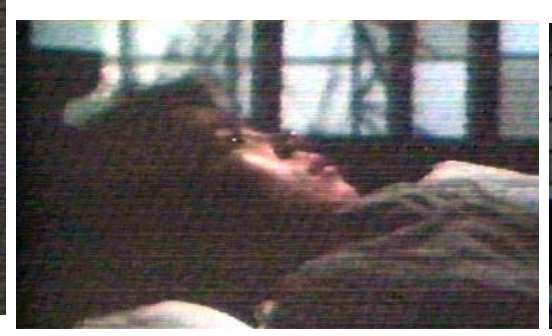

F20

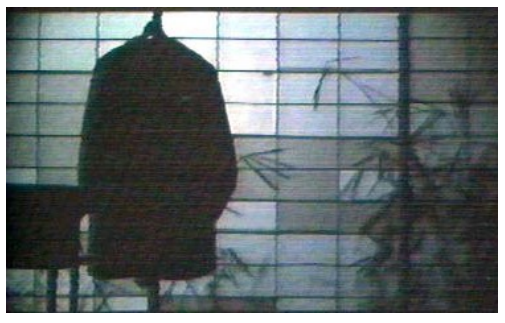

F21

Él se queda dormido, y ronca, como sucedía en aquella pieza clásica. La mujer, por el contrario, permanece despierta y solitaria. Pero esta vez no se muestra el famoso recipiente de porcelana, sino irónica y prosaicamente el abrigo de él, colgado de la 
pared (F21). La prenda suspendida en la percha remite a ejemplos ya vistos en Primavera tardía y, particularmente, en Primavera precoz. Pero interesa advertir que la situación de duermevela justifica acaso la quiebra del raccord: los dos están tumbados juntos, mirando hacia la derecha. En el siguiente plano, él mira hacia la izquierda, y ella mira hacia la derecha, presas acaso de un mismo delirio de naturaleza sensual.

Asimismo Masayuki practica el recurso de figuras igualadas (sojikei) mediante el montaje, en un recurso muy próximo al que se utilizó en El otoño de los Kohayagawa (Kohayagawa ke no aki, Yasujiro Ozu, 1961). En la estación del tren tanto el padre como Yuriko aparecen igualados, vestidos de negro, con una bolsa roja en la mano izquierda. Posteriormente se amplía el recurso de equiparación al hermano menor, que se encuentra junto a ambos. Finalmente el padre y los dos hermanos son vistos alineados, como en tantas otras escenas del maestro homenajeado, en una composición muy similar, por ejemplo, a las que abundan en Buenos días (Ohayo, Yasujiro Ozu, 1959) (F22).

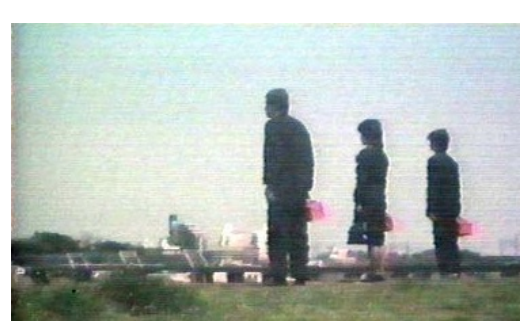

F22

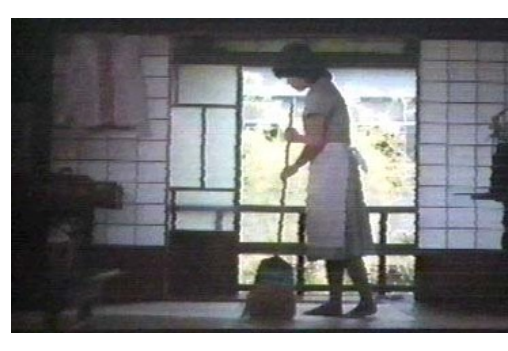

$\mathrm{F} 23$

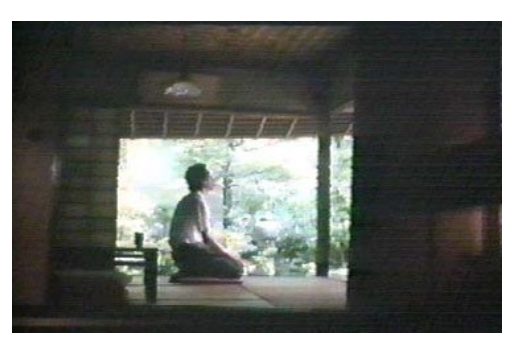

F24

Dislocando más si cabe el juego de referentes miméticos, el tramo final de la película es pródigo en situaciones disparatadas, aunque siempre concebidas bajo el patrón austero de Ozu. El marido se termina marchando con una de sus amantes, la misma que le flagela; Yuriko-san, su esposa, se venga acostándose con su cuñado. Aplicando todo el peso de la parodia, la mujer es aquí el equivalente ninfomaníaco de Noriko; incluso onomásticamente se hallan próximos. No ha enviudado, como la Noriko de Cuentos de Tokio, pero sí ha sido abandonada. Tras este desdichado episodio, Yuriko 
continúa cuidando del padre viudo, al que presta mayor atención que a cualquier otro miembro de la familia. Sin embargo, se mantiene leal al recuerdo -erótico- de su marido. Bástenos un ejemplo. Mientras hace la limpieza bajo un entorno espacial definido por los sobreencuadres característicos de Ozu, Yuriko encuentra un trozo del plástico que usaba el cónyuge desleal para atarla en la cama (F23). El hallazgo la devuelve los placeres experimentados en su compañía, de forma que lo frota por su seno, y se acaricia con él con delectación lúbrica. Mientras tanto el padre, solitario y ensimismado en el jardín, nos devuelve las imágenes conclusivas frecuentes de Ozu (F24).

También en el desenlace reconocemos la imagen de la escalera vacía que conduce hacia el piso superior, mientras el padre permanece en el jardín, como sucedía al final de Samma no aji (1962) En aquella ocasión era el camino de acceso a la habitación de la hija, que tras su boda quedaba desierta y abandonada. Nadie sube por los peldaños, como es regular en Ozu. Pero estos conducen a las dependencias superiores: el lugar donde dormía el matrimonio quebrado, y donde varias veces les sorprendimos haciendo el amor. Y aquí es donde ahora queda sola la mujer, solazándose a sí misma, sin más compañía que sus recuerdos.

Contrasta de este modo la primera con la última escena. En la primera la pareja copulaba en el piso superior, mientras el resto de la familia se reunía bajo ellos, espiándoles. En la escena final, por el contrario, el matrimonio se ha roto; y finalmente la familia se ha dispersado, como sucede en las tragedias familiares de Ozu. La mujer se recluye en el piso superior, el espacio normalmente reservado para las hijas solteras en Ozu. En el piso inferior ahora no se congrega la familia: sólo queda el padre, embriagado por sus tristes pensamientos y recuerdos. El anciano, decepcionado, sin esposa y rodeado de hijos viciosos, contempla ante sí el que bien puede ser el último episodio de una existencia en la que sólo contará con el consuelo del sake.

En conclusión: desde su comienzo hasta el último plano, todo el largometraje de Masayuki se ve alimentado por la voluntad paródica que, sumada al continuo juego 
de referencias intertextuales, han dado forma a un notable ejercicio mimético: una caricatura formal que, paradójicamente, no oculta la profunda admiración hacia las obras parodiadas. De manera consecuente, el desenlace brota a partir de la ironía sobre el sentimiento de resignación que invade a los personajes de Ozu y que, en el caso de la voluptuosa Yuriko, halla un pasajero alivio mediante la entrega al placer solitario.

Hentai kazoku: Aniki no o yomesan (Familia anormal: La mujer de mi hermano)

Guión y Dirección: Suo Masayuki. Intérpretes: Haruhiko Fukano (Shuzo Mamiya), Kaoru Kaze (Yuriko Mamiya), Ren Osugi (Shukichi Mamiya), Shirô Shimamoto (Koichi Mamiya), Kei Shuto (Kazuo Mamiya), Miki Yamaji (Akiko Mamiya), Kurara Hanayama (La joven esposa de Kiushu), Raibu Hara (El joven esposo de Kiushu). Usagi Aso (Dueña del bar).

Año de producción: 1983. Duración: 62 minutos.

\section{Referencias bibliográficas}

Arqués, R. (1979). "Del erotismo : Una definición”. Camp de l’Arpa, Junio, no 64, p. 5 .

Bordwell, D. (1988). Ozu and the Poetics of Cinema. New Jersey: Princeton University Press.

Bresson, r. (1997). Notas sobre el cinematógrafo. Madrid: Árdora.

Ehrlich, L. (1998 a). "Dancing for the fun of it: Conversation with Suô Masayuki". Japan Quarterly, January - March, p. 22.

Ehrlich, L. (1998 b). "Shall we dance?”. Asian cinema, Spring, pp. 96 - 97.

Freixas, R. \& bassa, J. (2000). El sexo en el cine y el cine de sexo. Barcelona: Paidós.

Hasumi, S. (1998). Yasujiro Ozu. Paris: Cahiers du Cinéma. 
Ishagpour, Y. (1994). Formes de l'impermanence: Le style de Yasujiro Ozu: Où l'on va au Japon pour revenir dans l'Occident de la présumée fin de l'Histoire. Bruselas: Yellow Now.

Lawrence, D.H. (1979). "Pornografía y obscenidad". Camp de l'Arpa, Junio, no 64, pp. 7 - 11 .

Miret, R. (1981). "Yasujiro Ozu: Primavera perenne de un cineasta intemporal". Dirigido por.... $\mathrm{n}^{\circ}$ 81, pp. 25-36 (primera parte).

Miret, R. (1981). "Yasujiro Ozu: Primavera perenne de un cineasta intemporal". Dirigido por.... $\mathrm{n}^{\mathrm{0}}$ 82, pp. 26-39 (segunda parte).

Oshima, N. (1992). Cinema, Censorship and the State: The Writings of Nagisa Oshima: 1956 - 1978. Cambridge (Massachusetts); London: The MIT Press.

Rayns, T. (1995). “Japan: Sex and Beyond”. Sight and Sound, June, v. 5, nº 6, pp. 2629.

Richie, D. (1974). Ozu. Berkeley: University of California Press.

Santos, A. (2010). En torno a Noriko: Primavera tardía, Principios de verano, Cuentos de Tokio. Valencia: Filmoteca; Instituto Valenciano de Cinematografía Ricardo Muñoz Suay.

Santos, A. (2012). Yasujiro Ozu: Elogio del silencio. Madrid: Cátedra.

Santos, A. (2014). Ozu: Tiempo de cine: Yasujiro Ozu en los tiempos de estruendo. Tomo I: El Todo y la Nada. Tokyo: Texnai.

Sontag, S. (1979). “La imaginación pornográfica”. Camp de l'Arpa, Junio, nº 64, pp. $21-24$.

Trías, E. (1979). “El Amor y la Muerte”. Camp de l’Arpa, Junio, nº 64, p. 35.

Yasujiro O. (1979). Valladolid: 24 Semana Internacional de Cine.

Yoshida, K. (2003). Ozu's Anti-Cinema. Ann Arbor: Center for Japanese Studies, University of Michigan. 